\title{
A unique case of segmental vasal atresia
}

\author{
This article was published in the following Dove Press journal: \\ Research and Reports in Urology \\ II November 2014 \\ Number of times this article has been viewed
}

Yasen Fayez Alalayet'

F Alkasim ${ }^{2}$

N Shiba'

I Aldhuayan ${ }^{2}$

S Alhamaidi'

G Alghamdi ${ }^{2}$

F Aljobair ${ }^{2}$

J Shoura'

R Alkhlaif ${ }^{2}$

'Department of Pediatric

Surgery, ${ }^{2}$ Department of

Pediatrics, King Saud Medical

City, Riyadh, Saudi Arabia
Correspondence: Yasen Fayez Alalayet Department of Pediatric Surgery, King Saud Medical City, Riyadh I I535, PO Box 59796, Saudi Arabia Email alalayet@netscape.net; alalayet_57@yahoo.com
Abstract: We report a case of a 2-year-old boy who presented with an empty left scrotum. Clinical examination revealed a left palpable undescended testis. During orchidopexy, segmental atresia of the vas deferens was found, and microsurgical repair was carried out. Segmental vasal atresia is an extremely rare condition and is infrequently diagnosed, especially in the pediatric age group. This is the first reported case of segmental vasal atresia without an association with cystic fibrosis.

Keywords: absence of vas deference, vasal anomalies, testis

\section{Case history}

A 2-year-old boy presented with a history of an empty left scrotum since birth.

General physical examination was unremarkable, and local examination revealed a left hypoplastic scrotum with a normal-sized left testis palpated in the groin. The right testis was normal in location and size. Routine blood investigations were within normal limits, and no abnormality was detected on abdominal ultrasound. A conventional orchidopexy was planned.

Orchidolysis was carried out through a left inguinal incision. Upon examination of the left testis and epididymovasal system, the left testis was found to be normal in size, shape, and consistency. A defect in the continuity of the vas deferens near the epididymis was found (Figure 1), in that the peritoneum opened over the vas deferens. A very thin fibrotic band connecting both ends of the vasal defect was isolated (Figure 2) and microsurgically resected by end to end anastomosis using 9-0 polyglactin (Figure 3 ) to establish normal vas continuity.

The result of a sweat chloride test was normal, and histopathology confirmed the fibrotic consistency of the resected band.

After a 1-month follow-up interval, the patient showed no respiratory or gastrointestinal symptoms of cystic fibrosis (CF). In addition, the family was counseled regarding the low possibility of infertility in the future.

\section{Discussion}

Segmental vasal atresia is an extremely rare congenital anomaly and has been infrequently reported in the pediatric age group. A range of vas deferens anomalies can be seen in cryptorchid patients, eg, congenital bilateral or unilateral absence of vas deferens and ectopic, duplication, diverticulum, or segmental aplasia of vas deferens. ${ }^{1}$ 


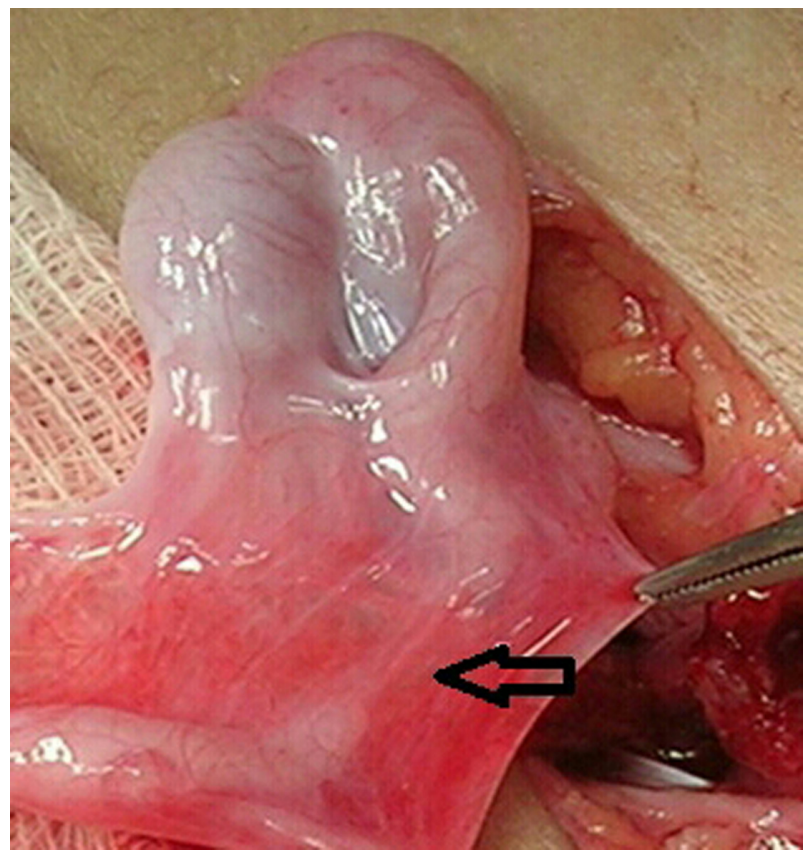

Figure I A defect in the continuity of the vas deferens near the epididymis. Note: Arrow shows vas defect.

The cryptorchid testicle has structural and functional alterations, and the rate of infertility is inversely proportional to the age at the time of orchidopexy. ${ }^{2}$ The highest fertility indexes are reported with therapy before the age of 2 years. ${ }^{3}$ Azoospermia is present in about $18 \%-20 \%$ of adults operated upon for bilateral cryptorchidism. The prognosis of future fertility should be considered when epididymovasal anomalies are detected at orchiopexy, and the incidence of epididymal and vasal abnormalities in undescended testicles is $(19 \%) .{ }^{4}$ Flimsy attachment of the head of epididymis to the testis constituted the most common anomaly. ${ }^{5}$

We could not find a similar segmental vasal atresia without CF in a review of the pediatric literature. It is advisable to

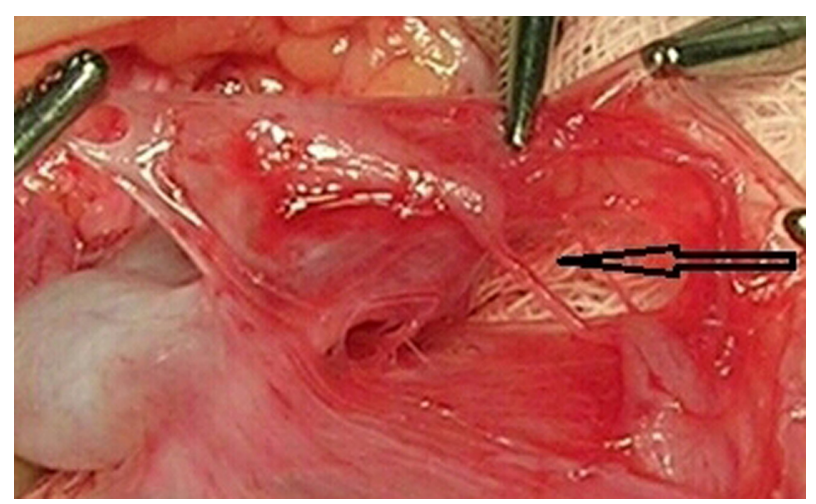

Figure 2 A very thin fibrotic band connecting both ends of the vasal defect was isolated.

Note: Arrow shows vas defect.

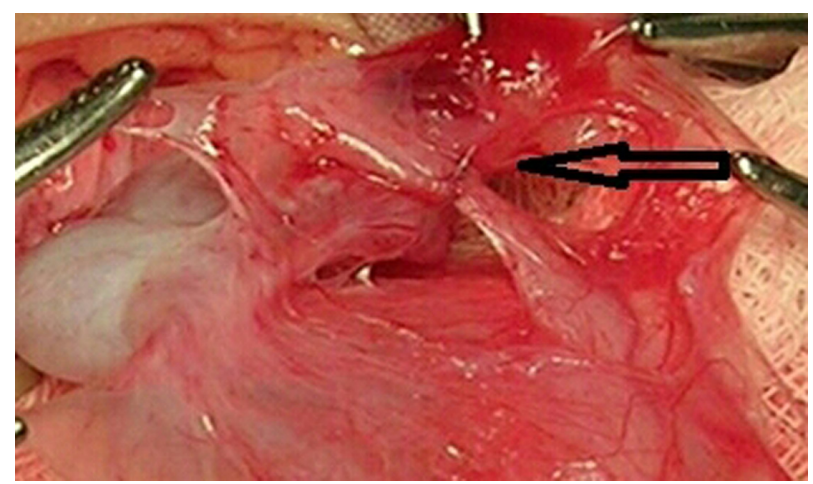

Figure 3 The thin fibrotic band connecting both ends of the vasal defect was microsurgically resected by end to end anastomosis using 9-0 polyglactin to establish normal vas continuity.

Note: Arrow shows vas defect.

evaluate the vas for its presence bilaterally and palpate along its entire length to check for defects preoperatively. Hunter reported congenital absence of the vas deferens (agenesis) as long ago as $1737 .{ }^{6}$ Congenital bilateral absence of the vas deferens (CBAVD) is a genital form of $\mathrm{CF}^{7} \mathrm{CBAVD}$ is a frequent cause of obstructive azoospermia, and is generated by mutations in the CF transmembrane conductance regulator gene. ${ }^{8}$ Also, congenital unilateral absence of the vas deferens has been reported. ${ }^{9}$ Approximately $10 \%$ of obstructive azoospermia is congenital and due to mutations in the $\mathrm{CF}$ gene. ${ }^{10} \mathrm{~A}$ small subset of men without known $\mathrm{CF}$ transmembrane conductance regulator defects may exhibit CBAVD. ${ }^{11}$

\section{Conclusion}

Segmental vasal atresia is a rare condition. Careful examination of the testis and epididymovasal system is essential to look for associated anomalies while, at the the same time, providing treatment.

\section{Disclosure}

The authors report no conflicts of interest in this work.

\section{References}

1. Radpour R, Gourabi H, Dizaj AV, Holzgreve W, Zhong XY. Genetic investigations of CFTR mutations in congenital absence of vas deferens, uterus, and vagina as a cause of infertility. J Androl. 2008;29(5):506-513.

2. La Vignera S, Calogero AE, Condorelli R, et al. Cryptorchidism and its long-term complications. Eur Rev Med Pharmacol Sci. 2009;13(5): 351-356.

3. Schwentner C, Oswald J, Kreczy A, et al. Neoadjuvant gonadotropinreleasing hormone therapy before surgery may improve the fertility index in undescended testes: a prospective randomized trial. $J$ Urol. 2005;173(3):974-977.

4. Belloli G, D'Agostino S, Campobasso P. Epididymal and vasal abnormalities in undescended testes and azoospermia. Pediatr Surg Int. 1994;9:95-98. 
5. Mollaeian M, Mehrabi V, Elahi B. Significance of epididymal and ductal anomalies associated with undescended testis: study in 652 cases. Urology. 1994;43(6):857-860.

6. Hunter J. On the glands called vesiculae seminales. In: Palmer JF, editor. Complete Works. Vol 4. London: Longman, Reese, Orm, Brown, Green, and Longman; 1737:20-34.

7. Vohra S, Morgentaler A. Congenital anomalies of the vas deferens, epididymis, and seminal vesicles. Urology. 1997;49(3):313-321.

8. Lopez E, Viart V, Guittard C, et al. Variants in CFTR untranslated regions are associated with congenital bilateral absence of the vas deferens. J Med Genet. 2011;48(3):152-159.
9. Rotman A, Hutson J. Congenital unilateral absence of the vas deferens. ANZ J Surg. 2010;80(3):197-198.

10. McCallum T, Milunsky J, Munarriz R, Carson R, Sadeghi-Nejad H, Oates R. Unilateral renal agenesis associated with congenital bilateral absence of the vas deferens: phenotypic findings and genetic considerations. Hum Reprod. 2001;16(2):282-288.

11. Havasi V, Rowe SM, Kolettis PN, et al. Association of cystic fibrosis genetic modifiers with congenital bilateral absence of the vas deferens. Fertil Steril. 2010;94(6):2122-2127.

\section{Publish your work in this journal}

Research and Reports in Urology is an international, peer-reviewed, open access journal publishing original research, reports, editorials, reviews and commentaries on all aspects of adult and pediatric urology in the clinic and laboratory including the following topics: Pathology, pathophysiology of urological disease; Investigation and treatment of

\section{Dovepress}

urological disease; Pharmacology of drugs used for the treatment of urological disease. The manuscript management system is completely online and includes a very quick and fair peer-review system, which is all easy to use. Visit http://www.dovepress.com/testimonials.php to read real quotes from published authors.

Submit your manuscript here: http://www.dovepress.com/research-and-reports-in-urology-journal 